\title{
Avaliação dos benefícios da ginástica localizada sobre a postura e a flexibilidade de mulheres na terceira idade
}

CDD. 20.ed. 796.018

796.4

\author{
Hélia Cristina Oliveira LIMA* \\ Jaina Bezerra de AGUIAR* \\ Paulo Fernando Machado PAREDES ${ }^{* *}$ \\ Luilma Albuquerque GURGEL*
}

*Universidade Estadual do Ceará.

*Faculdade Católica

Rainha do Sertão.

\section{Resumo}

Desvios posturais e redução na flexibilidade são alterações observadas com o avançar da idade, podendo desencadear dor e dificuldades de movimentação. Este estudo buscou avaliar a influência de um programa de ginástica, de dois meses de duração, sobre a postura e flexibilidade de idosas institucionalizadas $(n=10,60-75$ anos). A postura foi avaliada através do uso de simetrógrafo, fotografias e do teste de equilíbrio sagital pélvico, e a flexibilidade através do teste de sentar e alcançar. Cinco participantes modificaram a postura. Verificamos ainda redução da retroversão pélvica e aumento significativo ( $\mathrm{p}<$ $0,001)$ de flexibilidade. Concluímos que um programa de ginástica é capaz de melhorar as alterações posturais de idosas, assim como resgatar a flexibilidade.

Unitermos: Saúde do idoso; Exercício; Amplitude de movimento articular.

\section{Introdução}

O processo de envelhecimento de uma população se dá devido ao declínio sustentado de fecundidade. Alguns países, inclusive o Brasil, que apresentavam uma população extremamente jovem, tiveram um declínio da fecundidade, diminuindo os números anuais de nascimentos, dando início a um aumento da base da pirâmide etária (CARVAlHo \& GARCiA, 2003). Devido à redução na taxa de natalidade nos últimos anos e ao aumento global de envelhecimento da população, estima-se que os avanços da ciência e da tecnologia possibilitarão ao indivíduo viver 110 a 120 anos, uma expectativa de vida correspondente aos limites deste século (Veras \& CALDAS, 2004).

O envelhecimento está relacionado a heranças fisiológicas de cunho social ou cronológico, é um seguimento biossocial retroativo dos seres vivos, com manifestações de perda das capacidades ao longo da vida, geneticamente influenciado por fatores psico-emotivos e pelo estilo de vida do indivíduo (Franchi \& Montenegro Júnior, 2005). Os idosos são acometidos por mudanças anátomo-fisiológicas, como: perda de massa óssea e muscular, redução de força, baixa flexibilidade, lentidão na execução dos movimentos e oscilação corporal frequente na postura em pé, estando sujeitos a alterações posturais em virtude dessas mudanças (Pereira, 2006). No envelhecimento, as alterações posturais fisiológicas acontecem na senescência (FERREIRA, MasSote \& Lima, 2005).

Os desvios posturais são as causas mais importantes de morbidade na população, sendo resultados de fatores psicológicos, socioculturais e biológicos (Palhares, Rodrigues \& Rodrigues, 2001). Dentre as alteraçōes posturais características do indivíduo idoso, podemos citar: a cabeça se projeta para frente, a coluna vertebral torácica se curva para uma postura mais cifótica e há ainda uma perda da lordose lombar normal com retroversão pélvica (GUCCIONE, 2002).

A postura corporal de um indivíduo pode ser alterada utilizando-se de exercícios ou por meio de mudanças das propriedades musculares, sendo necessário mudar o ponto de equilíbrio desse conjunto de rigidez que age em certo seguimento do corpo. As dores na coluna vertebral, a estética corporal e degeneração da estrutura do corpo, são fatores ocasionados pela má postura. Mas com um tratamento ou intervenção precoce, há possibilidades de minimizar esse processo (FUNDEP, 2004). 
Algumas das modificaçóes na postura, ocasionadas por alteraçōes degenerativas durante o processo de envelhecimento biológico, são irreversíveis, como por exemplo, as decorrentes de encunhamento vertebral, achatamentos vertebrais isolados, degeneração dos discos intervertebrais e artrose da coluna (BARROS FILHO $\&$ Napoli, 2004). Contudo, tendo em vista que as alterações posturais são decorrentes não apenas de fatores estruturais, mas também funcionais, especificamente em idosos, certo grau de correção postural é possível com a prática regular de exercícios. De acordo com FERREIRA, MASSOTE e LiMA (2005), um programa de exercícios de alongamento segmentar passivo e exercícios resistidos foi capaz de aumentar de forma significativa a estatura corporal de idosos. Esses resultados estão de acordo com o estudo realizado por GRANITO, RENNO, Aveiro, Navega, Driusso e Oishi (2004), que através de um programa de treinamento físico, constituído de

\section{Metodologia}

\section{Amostra}

A pesquisa foi realizada em um asilo de idosos mantido por instituição filantrópica com mais de 120 anos de existência, localizado na cidade de Fortaleza, Ceará. A amostra foi formada por 10 mulheres, com idade de 60 a 75 anos, sedentárias e capazes de realizar suas atividades de vida diária independentemente. As idosas apresentavam as respectivas médias e desvios padrōes de peso, altura e IMC: $56,97 \pm 10,27 \mathrm{~kg}, 1,49$ $\pm 0,07 \mathrm{~m} \mathrm{e} 25,40 \pm 3,80 \mathrm{~kg} / \mathrm{m}^{2}$. Todas as participantes tiveram frequência de duas vezes por semana às aulas de ginástica localizada que passaram a ser ofertadas na instituição, durante dois meses, por profissional de educação física.

O grande número de idosas que não apresentavam condições físicas para a realização da atividade proposta, tendo em vista que poucas possuíam nível de independência suficiente para aderir ao estudo; a não participação dos homens às aulas de ginástica, possivelmente por motivos culturais e o pequeno número de mulheres que frequentaram com assiduidade as aulas dificultaram a obtenção de uma amostra mais representativa.

Constituíram critérios de exclusão: mulheres dependentes de auxílio de terceiros ou de órteses para realização das atividades básicas da vida diária, com alteraçôes no sistema locomotor, com déficit de compreensão, portadoras de doenças cardíacas caminhada e exercícios de alongamento, observaram aumento significativo na estatura corporal de mulheres com osteoporose. Nestes estudos, o ganho de estatura tem sido considerado como um indicativo de melhor alinhamento das curvaturas posturais.

O envelhecimento também proporciona redução da flexibilidade, ocasionando encurtamento muscular e aumentando o gasto energético durante a realização de atividades, como por exemplo, durante a locomoção. A ausência de movimentos amplos está associada à redução da flexibilidade, causando insegurança durante as atividades físicas, sendo frequentes as reclamaçōes de dores músculo-articulares durante a realização de atividades diárias (ACHOUR JúNIOR, 1999).

Através desta pesquisa buscou-se avaliar a influência de um programa de ginástica localizada e alongamento sobre postura e flexibilidade de idosas institucionalizadas.

descompensadas, infecciosas ativas, metabólicas e auto-imunes. As idosas foram submetidas a avaliação médica, para a identificação dos possíveis critérios de exclusão. O acompanhamento médico periódico faz parte da rotina da instituição, sendo registradas em prontuários as informaçôes colhidas pelo profissional. Para a seleção das participantes, os prontuários foram consultados e as idosas que se enquadravam no perfil da amostra foram convidadas a participar da pesquisa.

O protocolo de pesquisa foi aprovado pelo Comitê de Ética em Pesquisa da Universidade Estadual do Ceará (processo $n^{\circ} 06358651-7$ ) e as participantes demonstraram seu consentimento em participar do estudo através da assinatura de um termo de consentimento livre e esclarecido.

\section{Procedimentos}

A coleta de dados foi realizada individualmente, antes do início da aplicação do programa de ginástica localizada e dois meses após o início deste, seguindo a sequência: avaliação da cifose dorsal, avaliação da retroversão pélvica e avaliação da flexibilidade. As avaliadas receberam somente orientação verbal do avaliador para execução dos testes. As idosas foram orientadas a não praticar exercícios físicos por, no mínimo, 24 horas antes do horário estabelecido para a coleta. 


\section{Ginástica localizada}

As aulas, com duração de uma hora, foram realizadas duas vezes por semana, com utilização de bastôes $(0,5 \mathrm{~kg} ; 1 \mathrm{~kg} ; 2 \mathrm{~kg})$ e caneleiras $(0,5 \mathrm{~kg} ; 1$ $\mathrm{kg} ; 2 \mathrm{~kg}$ ) para a ginástica localizada. Os exercícios de ginástica foram: extensão de tronco (com bastão); remada curvada (com bastão); e extensão de joelhos (com caneleiras), de duas a três séries de 10 repetiçóes para cada segmento muscular. Todos os exercícios foram realizados com o grupo sentado em cadeiras, devido a grande dificuldade que essas idosas tinham em sentar-se no chão sobre os colchonetes. A ginástica localizada teve duração de 30 minutos e foi direcionada ao fortalecimento dos músculos: quadríceps da coxa, músculo eretor da coluna (iliocostal, longo, espinhal) e grande dorsal.

O tempo de duração dos exercícios de alongamento foi de 30 minutos, sendo 15 minutos antes e 15 minutos após a ginástica localizada. Os exercícios de alongamento foram realizados, nas posições de bipedestação e sentada, com ênfase maior nos músculos: isquiotibiais, músculos peitorais (maior e menor) e reto do abdome. Foram utilizados os seguintes exercícios: flexão do quadril com o joelho estendido e fletido, abdução horizontal de ombros, elevação escapular, hiperextensão de tronco, flexão lateral de tronco, abdução de ombros com cotovelo flexionado, abdução de quadril, flexão de joelho com quadril estendido, flexão plantar e dorsiflexão. Foi utilizada a técnica de alongamento ativo estático e as avaliadas foram orientadas a sustentar a posição ao final da amplitude de movimento por 30 segundos, foram utilizadas três repetições, com intervalo de repouso de 10 segundos.

\section{Avaliação postural}

A postura da região torácica das idosas foi avaliada através de fotografia digital, utilizando-se um simetrógrafo e um fio de prumo. Durante os testes de avaliação postural as avaliadas encontravam-se descalças e vestindo roupa de material leve e sem mangas, para possibilitar a visualização do acrômio. Para identificação de anteriorização da cabeça e protração da cintura escapular, foram marcados com lápis dermográfico o centro do lobo da orelha direita e o acrômio direito. Em seguida, o simetrógrafo foi colocado ao fundo da foto e o fio de prumo entre a avaliada e a câmera fotográfica. O fio de prumo foi posicionado passando ligeiramente à frente do maléolo lateral direito da avaliada, para a avaliação da postura por vista lateral, que foi realizada conforme descrito por Lippert, em 2003. A máquina fotográfica (DSC-W215, 12,1 megapixels, Sony®) foi posicionada em uma altura de $78,5 \mathrm{~cm}$ e a uma distância de 2,56 m do simetrógrafo. A avaliada foi colocada em posição ortostática, de lado para a avaliadora, a qual registrou a postura da idosa através de fotografias.

A avaliação da retroversão pélvica foi realizada através do teste de equilíbrio sagital pélvico (SANTOS, 2001). Para a realização deste teste, os olhos da avaliadora foram posicionados ao nível das cristas ilíacas das voluntárias, estando estas em posição ortostática e de perfil. Os dedos indicadores da avaliadora foram posicionados sobre a espinha ilíaca ântero-superior e a espinha ilíaca pósteroinferior da participante e foi verificado se ambas situavam-se em um mesmo plano horizontal ou se havia desequilíbrio, por estarem situadas em um plano oblíquo. Para garantir a reprodutibilidade das medidas, todas as avaliações foram realizadas por um único avaliador (BILlis, Foster \& Wright, 2003), além disso, nenhuma das avaliadas apresentava perfil antropométrico que dificultasse a identificação, através de palpação, das espinhas ilíacas. Neste teste, quando a espinha ilíaca ântero-superior encontrase em um plano mais elevado que a espinha ilíaca póstero-inferior, significa que a pelve está em retroversão e a situação contrária indica que a pelve está em anteversão. Para melhor interpretação dos resultados, consideramos retroversão de grau leve aquela em que a diferença de altura entre a espinha ilíaca ântero-superior e a espinha ilíaca pósteroinferior era igual ou inferior a $3 \mathrm{~cm}$, e retroversão de grau avançado aquela em que a diferença de altura era superior a $3 \mathrm{~cm}$. Para este cálculo, as espinhas ilíacas foram marcadas com lápis dermográfico e em seguida a distância de cada uma destas ao solo foi determinada utilizando-se esquadro $\left(90^{\circ}, 120\right.$ $\mathrm{cm}$, Lee Tools®). A diferença de altura entre os pontos foi então calculada por meio da subtração das distâncias obtidas.

\section{Avaliação da flexibilidade}

A flexibilidade foi avaliada pelo teste de WeLLs e Dillon (1952), também denominado teste de sentar e alcançar ("Sit-and-reach Test"), que é uma medida linear e quantitativa (WILDER, GreEne, Winters, LONG, GUbler \& EDLICH, 2006). O teste avalia a flexibilidade envolvendo a musculatura isquiotibial e a região lombar (DANTAS, 1995; Wells \& Dillon, 
1952). Para a realização do teste, a idosa sentou-se sobre um colchonete com os joelhos estendidos, membros inferiores levemente afastados com os pés apoiados na parede da caixa de madeira, cotovelos estendidos e ombros fletidos. Em seguida realizou flexão de tronco, avançando lentamente para frente com ambas as mãos (paralelas), tão longe quanto possível, mantendo essa posição momentaneamente. A participante foi orientada a respirar normalmente durante o teste e não prender a respiração. $\mathrm{O}$ resultado foi o ponto mais distante, $\mathrm{em} \mathrm{cm}$, atingido com as pontas dos dedos. O protocolo de teste foi baseado nas recomendações de ACHOUR JúNIOR (2002) para os procedimentos usuais do teste de sentar e alcançar, sendo a medida tomada três vezes e considerada apenas a maior delas.

\section{Resultados}

As participantes da pesquisa apresentaram média de idade \pm desvio padrão de $67,5 \pm 5,76$ anos.

Durante a avaliação inicial da postura através de vista lateral, verificou-se que todas as participantes apresentavam cifose torácica em graus variados, com ou sem protração da cintura escapular e anteriorização da cabeça. Após o período de aplicação do programa, das 10 mulheres avaliadas, cinco (50\%) modificaram a postura. As alteraçōes posturais percebidas foram as seguintes: uma participante apresentou redução da anteriorização da cabeça, duas apresentaram redução da anteriorização da cabeça e da protração da cintura escapular, uma apresentou redução da protração da cintura escapular e uma outra apresentou correção no alinhamento da articulação do quadril.

Verificamos também que todas as 10 integrantes do grupo (100\%) apresentavam algum grau de retroversão pélvica. Apesar do teste utilizado não nos permitir quantificar precisamente o grau de inclinação posterior da pelve, percebeu-se que metade do grupo $(50 \%)$ apresentava uma inclinação posterior leve, enquanto a outra metade do grupo (50\%)

\section{Análise estatística}

Após a realização dos testes, foram analisadas as diferenças entre as variáveis obtidas (cifose torácica, retroversão pélvica e alcance no teste de sentar e alcançar) antes e após o período destinado à prática de exercícios. Utilizou-se análise descritiva para comparação da postura das participantes e o programa de análise estatística Statistical Package for Social Science for Windows (SPSS), versão 16, para comparação entre os valores numéricos relacionados à flexibilidade. Para esta variável, foi realizado o teste de normalidade de Shapiro-Wilk e a distribuição dos dados foi considerada normal. Assim, aplicou-se o teste t para amostras pareadas. Foram considerados significantes valores de $\mathrm{p}<0,05$.

apresentava um grau mais avançado de inclinação posterior (FIGURA 1).

Após o período de dois meses destinado à ginástica e ao alongamento, verificamos que as cinco mulheres que apresentavam inicialmente uma pequena inclinação posterior progrediram para uma situação de equilíbrio no posicionamento da pelve (50\%), ou seja, passaram a apresentar a espinha ilíaca ânterosuperior e a espinha ilíaca póstero-inferior em um mesmo plano horizontal. Dentre as cinco mulheres que apresentavam inicialmente um grau avançado de retroversão pélvica, uma progrediu para uma situação de equilíbrio (10\%) e as demais (40\%) conseguiram redução acentuada do desvio (FIGURA 1).

Quanto à flexibilidade, no teste inicial, verificouse que a média de alcance apresentada pelo grupo foi de $12,10 \pm 4,70 \mathrm{~cm}$ (média \pm desvio padrão), passando para $24,30 \pm 5,90 \mathrm{~cm}$ (média \pm desvio padrão) após o período de prática dos exercícios ( $\mathrm{p}<0,0001$, Teste t de Student) (FIGURA 2). O valor de t para esta variável foi de 14,75. O ganho individual de alcance neste teste variou de nove a $16 \mathrm{~cm}$ (TABELA 1). 


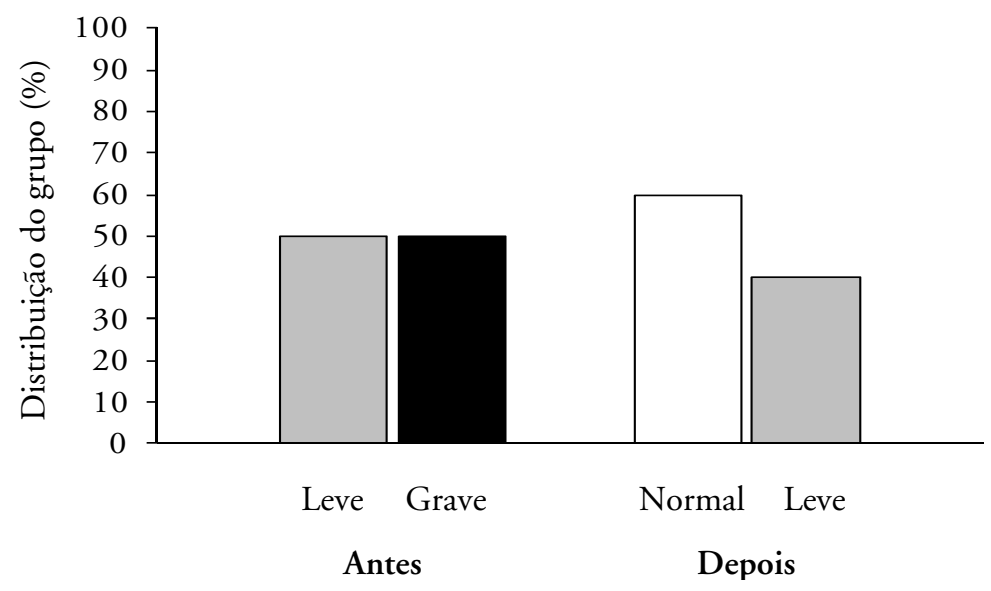

Leve $=$ retroversão de grau leve;

Grave = retroversão de grau avançado;

Normal = pelve em posição de equilíbrio.

FIGURA 1 - Distribuição percentual do grupo quanto ao posicionamento da pelve, antes e após a aplicação do programa de exercícios.

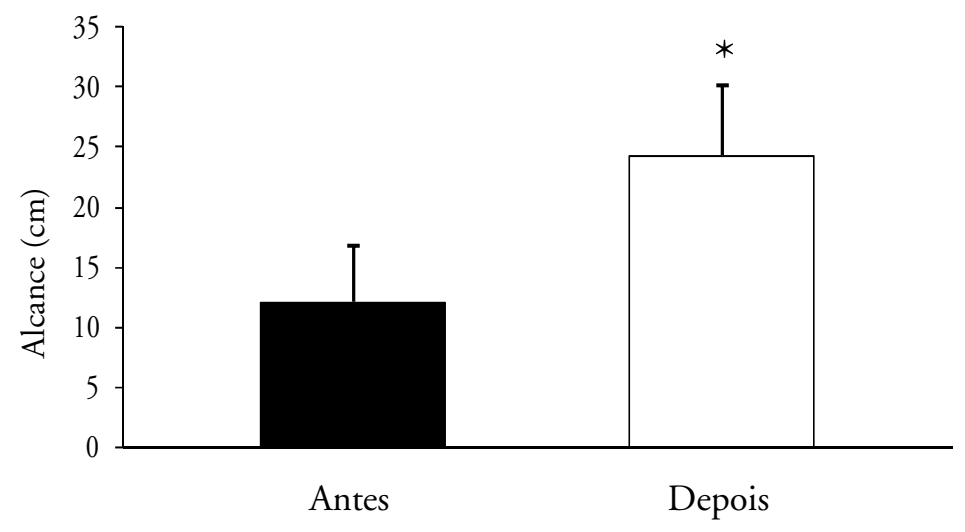

${ }^{*} p<0,0001$.

FIGURA 2 - Média ( \pm desvio padrão) do alcance do grupo, no teste de sentar e alcançar, antes e após o programa de exercícios.

TABELA 1 - Ganho individual de alcance $(\mathrm{cm})$ apresentado por cada integrante do grupo, no teste de sentar e alcançar, e sua correlação com a idade.

\section{Idade das avaliadas (anos)}

\section{Ganho de alcance $(\mathrm{cm})$}

$\begin{array}{ll}60 & 09 \\ 61 & 11 \\ 62 & 12 \\ 63 & 16 \\ 68 & 16 \\ 68 & 16 \\ 70 & 08 \\ 73 & 12 \\ 75 & 13 \\ 75 & 11 \\ & \end{array}$




\section{Discussão}

O processo de envelhecimento é caracterizado por alteraçôes posturais gradativas. A postura fletida em mulheres idosas é caracterizada pelo aumento da cifose torácica, anteriorização da cabeça e pelo declínio da altura (Balzini, Vannucchi, Benvenuti, Benucci, Monni, Cappozzo \& Stanhope, 2003; Ensrud, Black, HarRIS, ETTINGER \& CUMMINGS, 1997). A cifose aumenta de seis a 11 graus por década até os 50 anos de idade, até mesmo em mulheres que não apresentam fraturas vertebrais, e pode ser um fator de risco significante para futuras fraturas, independentemente de baixa densidade mineral óssea ou histórico de fraturas (ENSRUD et al., 1997; Huang, BarRetT-Connor, Greendale $\&$ KADO, 2006). A cifose torácica acentuada tem sido associada com dificuldade de executar atividades da vida diária e redução da performance física (BALZINI et al., 2003; HinMAN, 2004; RYAN \& FrIED, 1997; SinAKI, Itoi, Rogers, BergstralH \& WaHNER, 1996).

Apesar da etiologia precisa da postura fletida ser desconhecida, ela está associada a prejuízos músculo-esqueléticos, neuromusculares e sensoriais (BALZINI et al., 2003; ENSRUd et al., 1997; FERRUCCI, Bandinelli, Cavazzini, Lauretani, Corsi, Bartali, Cherubini, Launer \& Guralnik, 2004; Hinman, 2004). Redução da força dos extensores do tronco e da amplitude de movimento articular de ombros e quadris, por exemplo, têm sido associadas à postura fletida (BALZINI et al., 2003; SINAKI et al., 1996).

No presente trabalho, o grau de comprometimento da cifose não pôde ser mensurado quantitativamente em virtude da técnica utilizada, esta nos permitiu apenas verificar a existência ou não de uma redução do aumento da curvatura torácica, da anteriorização da cabeça e da protração da cintura escapular após dois meses de aplicação do programa de exercícios, através de análise comparativa de fotografias obtidas antes e após a aplicação do programa de ginástica localizada e alongamento.

Algumas limitações inerentes ao método de análise da postura (fotografias) devem ser ressaltadas no presente estudo. Apesar da análise ter sido realizada por uma única avaliadora, previamente treinada, algumas variáveis são de difícil observação, como o posicionamento do quadril e a posição do acrômio. Algumas referências demonstram a confiabilidade da análise através de fotografias, porém ressaltam a sua baixa reprodutibilidade (IunEs, Castro, Salgado, Moura, Oliveira \& Bevilaqua-Grossi, 2005).

Visando investigar a reprodutibilidade e confiabilidade da avaliação postural através de palpação, estudo realizado por Billis, Foster e Wright (2003) observou pobre reprodutibilidade entre avaliadores e boa confiabilidade intra-avaliadores. A confiabilidade da determinação de um ponto anatômico depende ainda da habilidade do avaliador, entretanto, em indivíduos muito obesos, a localização dos pontos pode ficar prejudicada dependendo do acúmulo de tecido adiposo no local. $\mathrm{Na}$ presente pesquisa uma mesma avaliadora realizou a identificação de todos os pontos anatômicos necessários à realização dos testes posturais, além disso, esta apresentava experiência e habilidade em avaliação postural e não encontrou dificuldade na palpação dos pontos ósseos necessários aos testes realizados.

Furlanetto, Chaise, Candotti e Loss (2009) realizaram estudo buscando avaliar o grau de reprodutibilidade da identificação, por palpação, de pontos anatômicos. Na pesquisa, 15 indivíduos foram submetidos a duas avaliações posturais, com intervalo de uma semana entre estas. As avaliaçôes, realizadas por um único avaliador, consistiram em palpação e marcação de pontos anatômicos utilizando marcadores reflexivos, em seguida foi realizado o registro fotográfico digital da postura ereta, nos planos sagital e frontal. Foram marcados pontos como acrômio, espinha ilíaca póstero-superior, espinha ilíaca ânterosuperior, trocânter maior do fêmur e côndilo lateral do joelho. A análise da postura foi realizada utilizando-se um software de avaliação postural e não foram verificadas diferenças significativas entre os dois dias de avaliação. Os achados indicam a reprodutibilidade da avaliação postural utilizando a palpação, quando esta é realizada por um mesmo avaliador.

Apesar das limitaçōes da técnica utilizada para fazer o acompanhamento da curvatura torácica da coluna, podemos perceber que mesmo tendo sido pequeno o tempo destinado ao programa de atividade física, já foram verificadas alteraçôes posturais que indicam uma possível melhora desta curvatura. Outros trabalhos realizados com mulheres idosas também investigaram a influência de programas de atividade física sobre a postura fletida do tronco, no entanto estes programas apresentaram duração maior que a utilizada neste estudo. ITOI e SINAKI (1994) relataram melhora da cifose em mulheres hipercifóticas, com idade entre 49 e 65 anos, após dois anos de uma intervenção de fortalecimento dos extensores do tronco. Em outro estudo, Katzman, Sellmeyer, Stewart, WANEK e HAMEL (2007) conseguiram reduzir a cifose, além de aumentar a força dos extensores de tronco, a 
performance física e a amplitude de movimento de ombros, quadris e joelhos de mulheres cifóticas com média de idade \pm desvio padrão de $72 \pm 4,2$ anos, após 12 semanas de exercícios.

A posteriorização da articulação do quadril apresentada por uma das participantes no presente estudo talvez possa ser explicada pelo fato da mesma passar grande parte do dia na posição sentada, o que pode ter levado a um encurtamento da musculatura flexora de joelho e quadril, comprometendo a sua postura.

Apesar de muitas vezes o aumento da curvatura torácica não ocorrer apenas por desequilíbrios musculares, mas sim por múltiplas fraturas compressivas na regiāo dos corpos vertebrais, facilitadas pelo processo de osteoporose que normalmente acompanha o envelhecimento, não temos dúvida que um programa de exercícios bem direcionado poderá amenizar tal desequilíbrio, contribuindo com a redução de dores nas regiôes torácica e lombar em virtude de uma má distribuição de pressões sobre os discos intervertebrais, favorecendo assim a realização das atividades de vida diária, além de contribuir com a estética corporal do idoso, melhorando sua autoestima. A redução da cifose deve causar benefícios longitudinais significativos ao idoso.

A posição da pelve é essencial para um bom alinhamento postural (Kendall, McCreary \& Provance, 1995; Kisner \& Colby, 1998; Norkin \& LeVANGIE, 2001). Em uma situação de cadeia cinética fechada, como na posição ortostática, a posição de um segmento influenciará na posição de segmentos adjacentes. Qualquer alteração no posicionamento normal da pelve causará movimentos compensatórios em regiōes próximas, sendo a coluna lombar e o quadril as primeiras a serem afetadas (Norkin \& LEVANGIE, 2001), o que poderá provocar dor. Portanto, a determinação da inclinação da pelve é importante para o acompanhamento da evolução de problemas na coluna.

A pelve sofre inclinação posterior com o avançar da idade (Takemitsu, Harada, Iwahara, Miyamoto \& Miyatake, 1988). O desenvolvimento deste quadro é preocupante, pois a posição funcional da pelve influencia a proporção da cobertura anteroposterior do acetábulo no desenvolvimento da coxartrose (JACobsen, Sonne-Holm, Lund, Soballe, Kiaer, RovSING \& Monrad, 2004; Jansen, AipPersbaCh, Munk, Sallomi, Garbuz, WeneK \& Hamel, 1998; NishiHara, Sugano, Nishit, Ohzono \& Yoshikawa, 2003; Olmedo-Garcia, Lopez-Prats, Agullo, Ortuño \& Palazon, 2000). Além disso, a manutenção de uma postura correta da região pélvica, ou seja, uma pelve estaticamente equilibrada nos planos frontal, sagital e horizontal (BIENFaIT, 2000), torna-se um fator de contribuição para a continência nas situaçõoes de aumento da pressão abdominal, pois favorecerá que essa pressão seja igualmente transmitida à bexiga e à uretra proximal, mantendo, assim, a pressão uretral máxima maior que a vesical (BIENFAIT, 1995).

Pelos resultados obtidos no presente estudo em relação ao posicionamento da pelve, apesar do pouco tempo destinado à atividade física, acreditamos que uma continuidade da mesma seria capaz de maximizar tais resultados, corrigindo, talvez, a postura pélvica de todo o grupo, o que poderia contribuir com a redução da incidência de lombalgias e consequentemente, melhoria da independência e qualidade de vida das idosas. Não foram encontrados na literatura estudos longitudinais sobre a influência de exercícios físicos na postura da pelve de mulheres na terceira idade.

A flexibilidade é um componente essencial da aptidão física. Geralmente, a diminuição da flexibilidade e da força nas regiōes sacro-ilíaca e abdominal, respectivamente, provoca lombalgias (PITANGA, 2004), sendo, portanto, importante a realização de estudos que busquem meios para minimizar estas alterações que ocorrem na terceira idade.

$\mathrm{O}$ teste de flexibilidade foi bem tolerado entre as idosas, apesar das mesmas encontrarem certa dificuldade para sentarem-se e levantarem-se do solo, ocasião em que receberam auxílio da avaliadora para evitar acidentes e minimizar a sensação de insegurança e desconforto.

Tendo em vista que o encurtamento dos isquiotibiais contribui com a rotação posterior da pelve, podemos inferir que a redução da retroversão pélvica mostrada no presente estudo pode estar relacionada ao ganho de flexibilidade conquistado pelo grupo.

Inicialmente, todas as integrantes do grupo apresentaram flexibilidade "muito fraca", segundo a tabela de classificação da flexibilidade de mulheres de acordo com o alcance $(\mathrm{cm})$ no teste de sentar e alcançar (ACMS, 2000). Após o período destinado ao programa de exercícios, verificamos que algumas mulheres ( $40 \%$ do grupo) apresentaram progresso quanto à classificação de sua flexibilidade. Duas integrantes do grupo passaram da classificação "muito fraca" para a classificação "fraca", uma passou para a classificação "alta" de flexibilidade e uma passou a apresentar flexibilidade "muito alta".

As médias de alcance obtidas nos testes realizados antes e após a aplicação do programa caracterizam a flexibilidade do grupo, respectivamente, como "muito fraca" e "fraca". Apesar do pequeno período destinado à prática de ginástica localizada e alongamento, 
verificamos que houve melhora da classificação da flexibilidade do grupo, uma vez que a média de alcance no teste de sentar e alcançar praticamente duplicou após a aplicação do programa. Mesmo não tendo atingido níveis considerados normais, os achados mostram que é possível minimizar perdas na flexibilidade induzidas pelo processo de envelhecimento. Os resultados são compatíveis com as informações produzidas por diversos autores que estudaram a influência da atividade física sobre a flexibilidade de idosas (CANDELORO \& Caromano, 2007; Cristopoliski, Sarraf, Dezan, Provensi \& Rodacki, 2008; Geraldes, AlbuQuerque, Soares, Carvalho \& Farinatti, 2008).

Esperávamos encontrar menores ganhos de flexibilidade entre as mulheres de idade mais avançada (idade $\geq 70$ anos), no entanto os valores obtidos pelas mulheres na faixa etária de 60 a 69 anos foram semelhantes àqueles obtidos pelas participantes com idade de 70 a 75 anos. Parece não haver correlação entre o ganho da flexibilidade e a idade das mulheres, pois os maiores ganhos de flexibilidade, 13 e $16 \mathrm{~cm}$, foram obtidos por mulheres com 73 e 75 anos e 63 e 68 anos, respectivamente, ao passo que os menores ganhos de flexibilidade, 8 e $9 \mathrm{~cm}$, foram obtidos por mulheres com idade de 68 e 60 anos, respectivamente.

Há necessidade de continuidade e progressividade do programa de exercícios físicos para que as idosas possam manter ou maximizar os ganhos obtidos, posto que pelo princípio da continuidade, uma interrupção no programa ocasionaria uma redução dos benefícios adquiridos (Tubino \& Moreira, 2003). A possível maximização dos ganhos, com a continuidade do programa, poderia aumentar a amplitude de movimento e reduzir a incidência de dores musculares resultantes de tensōes, melhorando assim o domínio físico da qualidade de vida destas pessoas.

\section{Conclusão}

Com o resultado desta pesquisa concluímos que um programa direcionado de ginástica localizada e alongamento é capaz de melhorar as alterações posturais comumente encontradas nos idosos, como cifose torácica acentuada, muitas vezes associada à protração escapular e anteriorização da cabeça, e retroversão pélvica; além de resgatar parte da flexibilidade perdida.
Portanto, é imprescindível que os asilos de idosos se conscientizem da importância do trabalho de profissionais que trabalhem com o movimento em seu quadro de funcionários/voluntários, pois a atividade física é um meio simples e de baixo custo capaz de promover saúde, independência e qualidade de vida nesta etapa de nossas vidas.

\section{Abstract}

Evaluation of the benefits of gymnastic in the posture and flexibility of old women

Ageing is associated with postural alterations and a decrease in flexibility, which results in pain and functional impairment among elders. The objective of this study was to evaluate the effectiveness of an exercise program, conducted during two months, in the posture and flexibility of old women $(n=10$, age $=60-75$ ). The posture was evaluated by symetrographic techniques, digital photography and the sagital pelvic balance test, and the flexibility through the sit-and-reach test. Five participants showed alterations in their postures. We verify the reduction of the pelvic retroversion and a significant increase $(p<0.001)$ in flexibility. We conclude that a gymnastics program is capable of correct some postural alterations of old women due to flexibility improvements.

UNITERMS: Health of the elderly; Exercise; Amplitude of articular movements. 


\section{Referências}

ACHOUR JÚNIOR, A. Bases para exercícios de alongamento relacionado com a saúde e no desempenho atlético. 2. ed. Londrina: Phorte, 1999.

. Exercício de alongamento, anatomia e fisiologia. São Paulo: Manole, 2002.

AMERICAN COLLEGE OF SPORTS MEDICINE (ACMS). ACSM's guielines for exercise testing and prescription. 6th ed. Baltimore: Lippincott, Williams \& Wilkins, 2000.

BALZINI, L.; VANNUCCHI, L.; BENVENUTI, F.; BENUCCI, M.; MONNI, M.; CAPPOZZO, A.; STANHOPE, S.J. Clinical characteristics of flexed posture in elderly women. Journal of the American Geriatrics Society, Malden, v.51, n.10, p.1419-26, 2003.

BARROS FILHO, T.E.P.; NAPOLI, M.M.M. Aspectos ortopédicos e traumatológicos. In: CARVALHO FILHO, E.T.; PAPALÉO NETTO, M. (Org.). Geriatria: fundamentos, clínica e terapêutica. São Paulo: Atheneu, 2004. p.319-27.

BIENFAIT, M. Os desequilíbrios estáticos. São Paulo: Summus, 1995.

. Fisiologia da terapia manual. São Paulo: Summus, 2000.

BILLIS, E.V.; FOSTER, N.E.; WRIGHT, C.C. Reproducibility and repeatability: errors of three groups of physiotherapists in locating spinal levels by palpation. Manual Therapy, London, v.8, n.4, p.223-32, 2003.

CANDELORO, J.M.; CAROMANO, F.A. Efeito de um programa de hidroterapia na flexibilidade e na força muscular de idosas. Revista Brasileira de Fisioterapia, São Carlos, v.11, n.4, p.303-9, 2007.

CARVALHO, J.A.M.; GARCIA, R.A. O envelhecimento da população brasileira: um enfoque demográfico. Cadernos de Saúde Pública, Rio de Janeiro, v.19, n.3, p.725-33, 2003.

CRISTOPOLISKI, F.; SARRAF, T.A.; DEZAN, V.H.; PROVENSI, C.L.G.; RODACKI, A.L.F. Efeito transiente de exercícios de flexibilidade na articulação do quadril sobre a marcha de idosas. Revista Brasileira Medicina do Esporte, Niterói, v.14, n.2, p.139-44, 2008.

DANTAS, E.H.M. Flexibilidade, alongamento e flexionamento. 3. ed. Rio de Janeiro: Shape, 1995.

ENSRUD, K.E.; BLACK, D.M.; HARRIS, F.; ETTINGER, B.; CUMMINGS, S.R. Correlates of kyphosis in older women: the Fracture Intervention Trial Research Group. Journal of the American Geriatrics Society, Malden, v.45, n.6, p.682-7, 1997.

FERREIRA, M.A.; MASSOTE, S.T.A.; LIMA, P.C. Aumento da estatura corporal no idoso através do tratamento postural. Textos sobre Envelhecimento, Rio de Janeiro, v.8, n.2, p.1-12, 2005.

FERRUCCI, L.; BANDINELLI, S.; CAVAZZINI, C.; LAURETANI, F.; CORSI, A.; BARTALI, B.; CHERUBINI, A.; LAUNER, L.; GURALNIK, J.M. Neurological examination findings to predict limitations in mobility and falls in older persons without a history of neurological disease. The American Journal of Medicine, Tucson, v.116, n.12, p.807-15, 2004. FRANCHI, K.M.B.; MONTENEGRO JÚNIOR, R.M. Atividade física: uma necessidade para a boa saúde na terceira idade. Revista Brasileira em Promoção da Saúde, Fortaleza, v.18, n.3, p.152-6, 2005.

FUNDAÇÃO DE DESENVOLVIMENTO DA PESQUISA (FUNDEP). Como mudar a postura corporal. 2004. Disponível em: <http://www.fundep.ufmg.br/homepage/cases/501.asp >. Acesso em: 24 jan. 2009.

FURLANETTO, T.S.; CHAISE, F.O.; CANDOTTI, C.T.; LOSS, J.F. Fidedignidade de um protocolo de avaliação postural. Revista Ciência \& Saúde, Porto Alegre, n.1, p.43, 2009. Edição Especial.

GERALDES, A.A.R.; ALBUQUERQUE, R.B.; SOARES, R.M.; CARVALHO, J.; FARINATTI, P.T.V. Correlação entre flexibilidade das articulaçôes glenoumerais e coxofemorais e o desempenho funcional de idosas fisicamente ativas. Revista Brasileira de Fisioterapia, São Carlos, v.12, n.4, p.274-82, 2008.

GRANITO, R.N.; RENNO, A.C.M.; AVEIRO, M.C.; NAVEGA, M.T.; DRIUSSO, P.; OISHI, J. Efeitos de um programa de atividade física na postura hipercifótica torácica, na dorsalgia e na qualidade de vida de mulheres com osteoporose. Revista Brasileira de Fisioterapia, São Carlos, v.8, n.3, p.231-7, 2004.

GUCCIONE, A.A. Fisioterapia geriátrica. 2. ed. Rio de Janeiro: Guanabara Koogan, 2002.

HINMAN, M.R. Comparison of thoracic kyphosis and postural stiffness in younger and older women. The Spine Journal, San Francisco, v.4, n.4, p.413-7, 2004.

HUANG, M.H.; BARRETT-CONNOR, E.; GREENDALE, G.A.; KADO, D.M. Hyperkyphotic posture and risk of future osteoporotic fractures: the Rancho Bernardo study. Journal of Bone and Mineral Research, Durham, v.21, n.3, p.419-23, 2006.

ITOI, E.; SINAKI, M. Effect of back-strengthening exercise on posture in healthy women 49 to 65 years of age. Mayo

Clinic Proceedings, Rochester, v.69, n.11, p.1054-9, 1994. 
IUNES, D.H.; CASTRO, F.A.; SALGADO, H.S.; MOURA, I.C.; OLIVEIRA, A.S.; BEVILAQUA-GROSSI, D. Confiabilidade intra e interexaminadores e repetibilidade da avaliação postural pela fotogrametria. Revista Brasileira de Fisioterapia, São Carlos, v.9, n.3, p.327-34, 2005.

JACOBSEN, S.; SONNE-HOLM, S.; LUND, B.; SOBALLE, K.; KIAER, T.; ROVSING, H.; MONRAD, H. Pelvic orientation and assessment of hip dysplasia in adults. Acta Orthopaedica Scandinavica, London, v.75, n.6, p.721-9, 2004. JANZEN, D.L.; AIPPERSBACH, S.E.; MUNK, P.L.; SALLOMI, D.F.; GARBUZ, D.; WERIER, J.; DUNCAN, C.P. Three-dimensional CT measurement of adult acetabular dysplasia: technique, preliminary results in normal subjects, and potential applications. Skeletal Radiology, New York, v.27, n.7, p.352-8, 1998.

KATZMAN, W.B.; SELLMEYER, D.E.; STEWART, A.L.; WANEK, L.; HAMEL, K.A. Changes in flexed posture, musculoskeletal impairments, and physical performance after group exercise in community-dwelling older women. Archives of Physical Medicine and Rehabilitation, New York, v.88, n.2, p.192-9, 2007.

KENDAL, F.P.; McCREARY, E.K.; PROVANCE, P.G. Músculos provas e funções. 4. ed. São Paulo: Manole, 1995.

KISNER, C.; COLBY, L.A. Exercícios terapêuticos: exercícios e técnicas. 3. ed. São Paulo: Manole, 1998.

LIPPERT, L.S. Cinesiologia clínica para fisioterapeutas. 3. ed. Rio de Janeiro: Guanabara Koogan, 2003.

NISHIHARA, S.; SUGANO, N.; NISHII, T.; OHZONO, K.; YOSHIKAWA, H. Measurements of pelvic flexion angle using three-dimensional computed tomography. Clinical Orthopaedics and Related Research, New York, n.411, p.140-51, 2003.

NORKIN, C.C.; LEVANGIE, P.K. Articulações estruturas e função: uma abordagem prática e abrangente. 2. ed. Rio de Janeiro: Revinter, 2001.

OLMEDO-GARCIA, N.; LOPEZ-PRATS, F.; AGULlO, A.; ORTUÑO, A.; PALAZON, A. A comparative study of the accuracy of Ranawat's and Pierchon's methods to determine the centre of rotation in bilateral coxopathy. Skeletal Radiology, New York, v.29, n.11, p.652-5, 2000.

PALHARES, D.; RODRIGUES, J.A.; RODRIGUES, L.M. Método simplificado de exame postural. Brasília Médica, Brasília, v.38, n.2/4, p.27-32, 2001.

PEREIRA, C.A. Manutenção da postura durante as AVDs em idosos: ação dos exercícios físicos no sistema proprioceptivo. 2006. 49 f. Monografia (Especialização em Ginástica Especial Corretiva) - Centro Universitário, Faculdades Metropolitanas Unidas, São Paulo, 2006.

PITANGA, F.J.G. Testes, medidas e avaliação em educação física e esportes. São Paulo: Phorte, 2004.

RYAN, S.D.; FRIED, L.P. The impact of kyphosis on daily functioning. Journal of the American Geriatrics Society, Malden, v.45, n.12, p.1479-86, 1997.

SANTOS, A. Diagnóstico clínico postural: um guia prático. 3. ed. São Paulo: Summus, 2001.

SINAKI, M.; ITOI, E.; ROGERS, J.W.; BERGSTRALH, E.J.; WAHNER, H.W. Correlation of back extensor strength with thoracic kyphosis and lumbar lordosis in estrogen-deficient women. American Journal of Physical Medicine \& Rehabilitation, London, v.75, n.5, p.370-4, 1996.

TAKEMITSU, Y.; HARADA, Y.; IWAHARA, T.; MIYAMOTO, M.; MIYATAKE, Y. Lumbar degenerative kyphosis: clinical, radiological and epidemiological studies. Spine, Philadelphia, v.13, n.11, p.1317-26, 1988.

TUBINO, M.J.G.; MOREIRA, S.B. Metodologia científica do treinamento desportivo. 13. ed. São Paulo: Shape, 2003. VERAS, R.P.; CALDAS, C.P. Promovendo a saúde e a cidadania do idoso: o movimento das universidades da terceira idade. Ciência \& Saúde Coletiva, Rio de Janeiro, v.9, n.2, p.423-32, 2004.

WELLS, K.F.; DILLON, E.K. The site and reach: a test of back and leg flexibility. Research Quarterly for Exercise and Sport, Washington, v.23, p.115-8, 1952.

WILDER, R.P.; GREENE, J.A.; WINTERS, K.L.; LONG, W.B.3RD.; GUBLER, K.; EDLICH, R.F. Physical fitness assessment: an update. Journal of Long-Term Effects of Medical Implants, New York, v.16, p.193-204, 2006.

ENDEREÇO

Luilma Albuquerque Gurgel

Centro de Ciências da Saúde

Universidade Estadual do Ceará Av. Dedé Brasil, 1700

60740-903 - Fortaleza - CE - BRASIL e-mail: luilmagurgel@yahoo.com.br
Recebido para publicação: 19/05/2009

1a. Revisão: 08/02/2010

2a. Revisão: 26/03/2010

3a. Revisão: 28/05/2010

4a. Revisão: 06/06/2010

Aceito: 14/06/2010 